NASA Technical Memorandum 81423

\title{
EXPERIMENTAL RESULTS ON PLASMA INTERACTIONS WITH LARGE SURFACES AT HIGH VOLTAGES
}

Norman T. Grier

Lewis Research Center

Cleveland, Ohio

- Prepared for the Eighteenth Aerospace Sciences Meeting sponsored by the American Institute of Aeronautics and Astronautics Pasadena, California, January 14-16, 1980
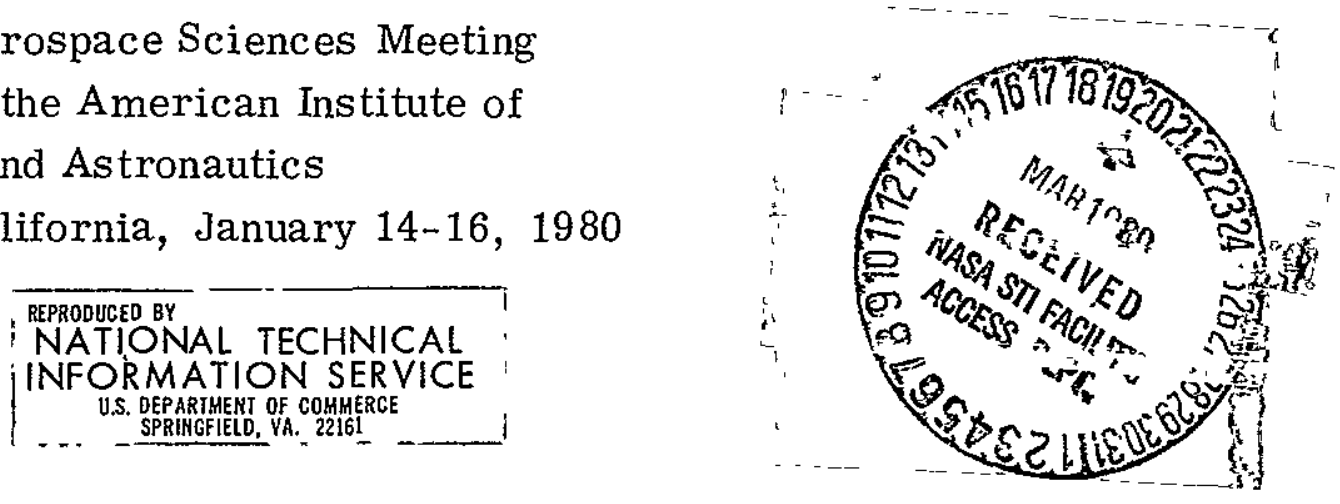


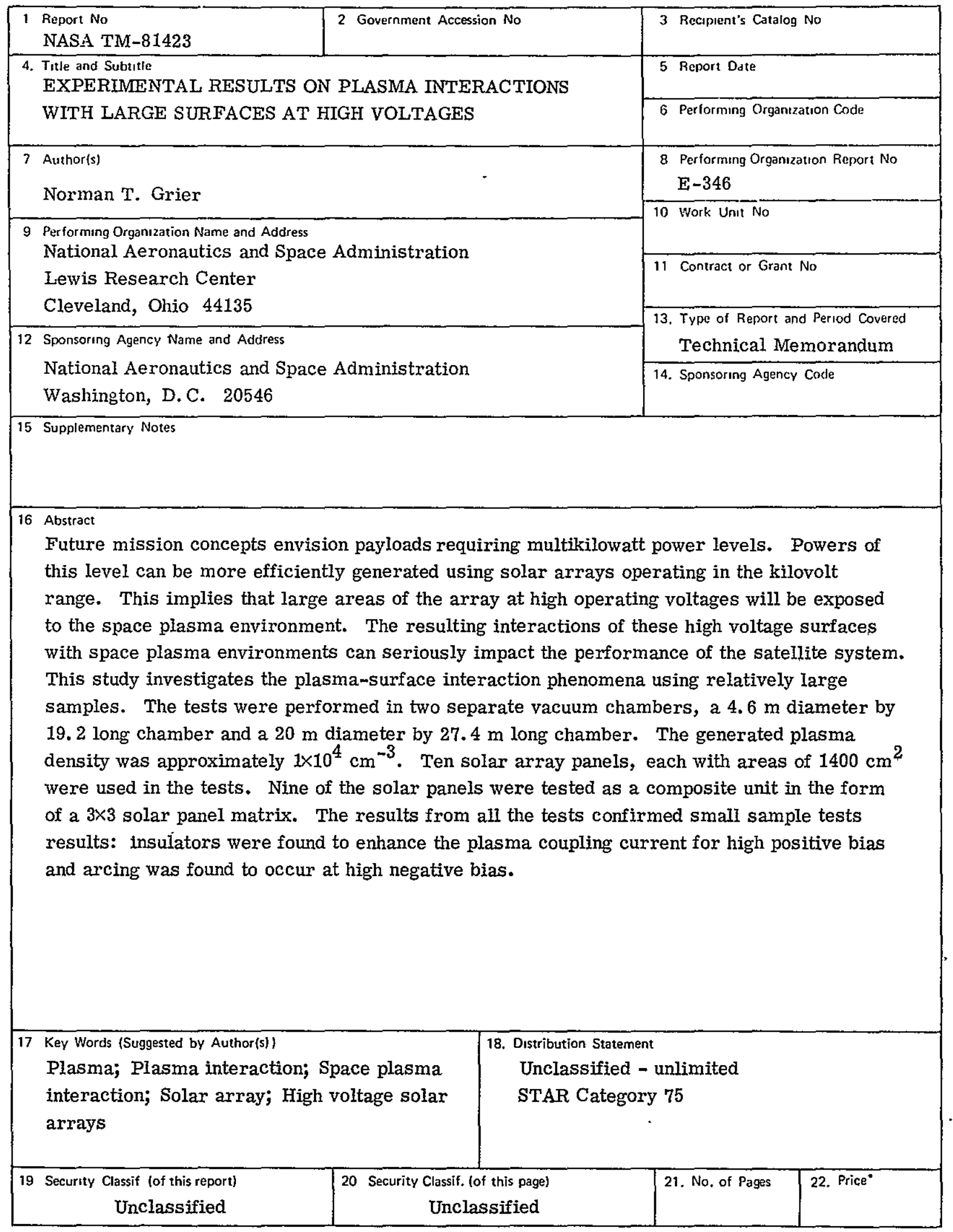

* For sale by the Natıonal Technical Informatıon Service. Springfield. Virgina 22161 
EXPERIMENTAL RESULTS ON PLASMA INTERACTIONS WITH LARGE SURFACES AT HIGH VOLTAGES

\author{
Norman T. Grier" \\ NASA Lewis Research Center \\ Cleveland, ohio 44135
}

\section{Abstract}

Future mission concepts envision payloads requiring multikilowatt power levels. Powers of this level can be more efficiently generated using solar arrays operating in the kilovolt range. This $1 \mathrm{~m}^{-}$ plies that large areas of the array at high operating voltages will be exposed to the space plasma environment. The resulting interactions of these high voltage surfaces with space plasma environments can seriously impact the performance of the satellite system. This study investigates the plasma-surface interaction phenomena using relatrvely large samples. The tests were performed in two separate vacuun chambers, a 4.6 m diameter by $19.2 \mathrm{~m}$ long chamber and a $20 \mathrm{~m}$ diameter by $27.4 \mathrm{~m}$ long chamber. The generated plasma density was approximately $1 \times 10^{4} \mathrm{~cm}^{-3}$. Ten solar array panels, each with areas of $1400 \mathrm{~cm}^{2}$ were used in the tests. Nine of the solar panels were tested as a composite unit in the form of a $3 \times 3$ solar panel matrix. The results from all the tests confirmed small sample tests results: insulators were found to enhance the plasma coupling current for high positive bias and arcing was found to occur at high negative bias.

\section{Introduction}

Future missions concepts envision very large, high power systems to be orbited in either low Earth orbit or at geosynchronous altitudes. These concepts embody solar array powers of $25 \mathrm{~kW}$ and higher. For these high levels of power, there must be an increase in the operating voltage from the present day level if the weight and harness losses are to be minimized. Operating voltages up to 45 $\mathrm{kV}$ have been proposed. 1 At such high voltage and power levels, large areas of solar array with kilovolts on them will be exposed to the plasma environment. The interaction of these hxgh voltage surfaces with the space plasma can seriously impact the performance of the power system. Therefore detalled understanding of the surface-plasma interaction phenomena are required before these systems become feasible.

Previous plasma interaction studies vere $1 \mathrm{im}$ ited to small samples. 2-9 Used in these studies were samples that simulated the front side and pinhole imperfections on the back side of solar ar rays. In some tests small solar array pane1s were. used. All these samples were tested by biasing them with an external powex supply and measuring the plasma coupling current. Two main results were found: (1) for positive bias voltages above about 100 volts on samples that have their electrode exposed to the plastma and surxounded by an insulator, have a leakage current that is greatly increased by the insulator, and (2) for the small solar array samples that were biased negatively, arcing to the plasma occurred for hrgh bias voltages. These arcs were observed for bias voltages as. low as 300 volts. Associated with these arcs were large surges of current which sometimes tripped off the power supply. If the large current for positive bias and arcing for negative bias continue to occur for large samples, then these may be the limiting factors for the operating voltages for the high voltage solar arrays of standard construction.

The present studies involved testing relatively large samples. An array consisting of nine 37 $\mathrm{cm} \times 38 \mathrm{~cm}$ solar panels arranged to form a $3 \times 3$ solar panel matrix was used. In addition, three other samples were tested; (1) a single solar panel that was the same size as one of the panels in the 9-panel matrix; (2) a 61-cm diametex fiberglass disk whth a $3.6 \mathrm{~cm}$ dianeter electrode in its center; and (3) a $3.6 \mathrm{~cm}$ diameter electrode without any surrounding insulation. Except for the plain disk sample, these samples were much larger than any of the samples previously tested. To insure that the sheath that is formed around the samples at high voltages could expand without wall interference, the same samples were tested in a large vacuum facility at NASA Lewis Research Center (LeRC) and checked in a much larger vacuum facility at NASA Johnson Space Flight Center (JSC).

The results from these tests will aid in devising scaling laws for the current collection, help in determining the sample size limitation of the LeRC facility, and also help in determinung whether the current enhancement and arcing is worse for very large solar arrays.

\section{Test Samples}

A 61-cm diameter disk with a $3.6 \mathrm{~cm}$ diameter electrode, a $3.6 \mathrm{~cm}$ diameter electrode without surrounding insulation, and 10 solar panels were used in the tests. $A$ cross-scctional view of the fiberglass disk is shown in F1g. $1(a)$. The electrode was made of stainless steel and gold coated on top. All the solar array panels had $0.015 \mathrm{~cm}$ (6mils) microsheet over each cell. Standard silver 2-bar interconnect construction was used between the cells (fig. 1(b)). These intexconnects were left bare and served as the current collection areas on the solar array panels. The solar panels were constructed to flight specifucations and originally served as back-up panels or were used in qualification testing for either the Space Electric Rocket Test (SERT) II or the Space Plasma High Voltage Interaction Experiment (SPHINX) satellite. There were eight SERT II type panels each approximately $1400 \mathrm{~cm}^{2}$, and two SPHINX type panels each consisting of approximately $1950 \mathrm{~cm}^{2}$. The interconnect area correspond to about 10 percent of the total panel area in each case. The SERT II type consisted of $3702 \times 2 \mathrm{~cm} \mathrm{~N} / \mathrm{P}$ solar cells and the SPHINX type consisted of $640 \mathrm{~lx} 2 \mathrm{~N} / \mathrm{P}$ solar cells.

Nine panels, seven SERT II type and two SPHINX type, were mounted on an aluninum grating structure

*Aerospace Engineer. 
to form a $3 \times 3$ matrix of solar array panels. The panels in this matrix will be referred to by panel number as shown in Fig. 1(c). The panels were electrically isolated from the aluminum grating using $1.9 \mathrm{~cm}$ long ceramic isolators. A picture of the 9-panel array, the $61 \mathrm{~cm}$ riberglass disk, and the single solar array panel mounted in the $\mathrm{l}_{\mathrm{R}} \mathrm{RC}$ facility is shown in Fig. 2. Both the positive and negative terminals on each panel were brought to a texminal strip outside the vacuum chamber. This allowed any series or parallel connections or groupings of the panels to be achreved. This also allowed the current to each individual panel or to a particular group of panels to be measured.

Another solar array pane1, a SERT II type, was tested singly. A comparison of the data from this panel with that of the 9-panel array shows the effect of the surrounding panels on the collection current.

\section{Facilities}

The tests were performed in two different vacuum facilities, one located at NASA LeRC and the other located at NASA JSC. The vacuum facility at LeRC was $4.6 \mathrm{~m}$ in diameter and $19.2 \mathrm{~m}$ long. The vacuum chamber at JSC was $20 \mathrm{~m}$ in diameter and 27.4 $m$ long. In each facility the ambient pressure was approximately $5 \times 10^{-6}$ torr. In the LeRC facility the 9-panel matrix faced axially and the single solar panel and the disk faced radially when mounted in the chamber as shown in Fig. 2. At JSC all panels, including the 9-panel matrix, faced radially towaxd the center of the chamber (fig. 3), These were mounted on a ring whose circumference was located about $9.1 \mathrm{~m}$ from the chamber floor and $3 \mathrm{~m}$ from the vertical side wall.

The plasma at JSC was generated from a $30 \mathrm{~cm}$ diameter Kaufman ion thruster using argon gas. The accelerating and decelerating grids on the thruster were left floating. Operating the thruster in this manner, the thruster was capable of gererating plasma densities from $10^{4}$ to $10^{6} \mathrm{~cm}^{-3}$. The source was located in the center of the floor of the chamber.

At LeRC the plasma was generated using a Pennungton type discharge tube. This source was capable of generating plasma densitics up to $10^{5}$ $\mathrm{cm}^{-3}$. A cross sectional view of this plasma source is shown in Fig. 4. The source was operated with an anode voltage of 50 volts. A baffle was used to spread the plasma throughout the chamber. This baffle also prevented any line of sight between. the samples and cathode filament of the source. Both argon and nitrogen gases were used in this source. In both facilities langmuir spheres were used to diagnose the plasma.

In some of the tests at JSC, a solar simulator was used in testing the 9-panel solar matrix. The simulator consisted of two circular beam carbon arcs mounted on the side wall opposite the 9-panel matrix sample. The arcs were adjusted for an intensity of one solar constant at the panel location. All panels were fully illuminated except for two small triangular shaped areas on panels number 2 and 8 in the matrix. These truangular areas were the areas left from using two circular arc lamps to illuminate the square shaped area of the 9-panel matrix. No solar simulation was used in. the LeRC rests.

\section{Procedure}

All the tests except some of those with illumination at JSC were performed by externally biasing the samples. The voltage was slowly increased while the current was measured with an electrometer between the power supply and the sample. 'Both' positive and negative biases were used in the tests. The bias voltages applied to the array were $2 \pi$ the range $\pm 1 \mathrm{kV}$ (less if the power supply tripped). The disks were biased to $+2.5 \mathrm{kV}$. For the solar simulation tests the 9-panel matrix was tested floating, grounded, and biased with an external power supply. With illumination the 9-panel watrix had an open circuit voltage of $260 \mathrm{~V}$ and a short circuit current of $43 \mathrm{~mA}$. This low short circuit current was probably due to two of the panels in the series not being fully illuminated.

\section{Results and Discussion}

\section{Positive Bias}

Disk experiments. The plasma coupling current as a function of positive applied voltage for the 61-cm diameter fiberglass disk is shown in Fig. 5 . Two tests are shown for the LeRC facility, one with argon plasma and the other with nitrogen plasma: As can be seen the type of gas makes no discernable difference. The JSC tests were run only in an argon plasma. From FIg. 5 it is seen that there is a large variation in the data for voltages below 200 v. In both the LeRC tests, the coupling currents were approximately an order of magnitude lower than JSC test data in the low voltage range. Although this difference is rather large, no sugnificance can be placed on it since differences of this magnitude have also been observed between different runs at LeRC.

The large increase in current seen for voltages between 100 and 500 volts is due to the insulator surrounding the electrode (area ef-

fect). $3-5$ In order to see clearly the effect of the insulator, the plain disk and the $61 \mathrm{~cm}$ diameter samples results are shown in Fig. 6 . In additron, the ground test data for the kapton disk experiment for the PIX satellite ${ }^{2}$ are also shown on this figure. The kapton disk sample was of the same type construction as the fiberglass disk except fox a sheer of $0.0127 \mathrm{~cm}$ thick kapton was used to cover the top of the fiberglass substrate. The kapton disk was $20.3 \mathrm{~cm} 2 n$ diameter with a gold coated electrode the same size as those in the present tests. From this figure, it is seen that the kapton disk and the fiberglass disk results are very close at the high voltages. The current collected is approximately 6.5 times higher than those for the plain disk in this voltage range. A simple probe calculation indicates that the effective electrode area for the disks with insulation is about $310 \mathrm{~cm}^{2}$. Thus the dominant effect of the surrounding insulator on current collection apparently occurs within a radius of approximately $10 \mathrm{~cm}$ or a distance of $8.2 \mathrm{~cm}$ beyond the electrode. Also from Figs. 5 and 6 , it is noticed that after the current has made its jump, it varies approximately linearly with voltage thereafter. According to probe theory this type of variation occurs for constant probe areas. This implies that for the $E \hat{i}-$ berglass disk and kapton disk samples, after the current has made its jump the effective current collection area remain constant with voltage. 
For voltages below $100^{\circ}$ volts the plain disk results are highex than the fiberglass and the kapton disks results. This agrees with previously found reslits that insulators suppress electron current collection at low voltages.

Single solar array panel. The electrodes for the solar panels are the interconnecting tabs between each solar cell. Therefore surrounding the electrodes are the insulating cover glass of each solar cell. The plasma coupling current-voltage characteristics for the single solar panel is shown in Fig. 7. A large variation in the data from zun to run for voltages below $100 \mathrm{~V}$ are observed for this sample also. Factors causing the large irreproducibility in the data in this voltage range have not been investigated. It is known that the surrounding insulator causes a suppression in electron collection. The same insulator causes an enhancement of the current at higher voltages as can be seen from the steep rise in current for voltages between 100 and 300 volts. At higher voltages, the current rises linearly with voltage indicating the whole array is collecting current as a solid electrode.

In the JSC tests, an unusual phenomenon occurred. When the voltage was raised above $400 \mathrm{~V}$, an oscillating glow type discharge occurred between the panel and the surrounding plasma. The current increased by a factor of hundred or more and was very unstable. This caused the power supply to trip off and so the test was teminated. This type of discharge has not been observed in the LeRC facility.

- Nine panel solar array matrix. The current voltage characteristics for the 9-panel array is shown in Fig. 8 for tests performed at LeRC and JSC. The current increases rather steeply, with voltage up to a voltage of approximately $200 \mathrm{~V}$. Above $200 \mathrm{~V}$ the increase is more gradual and is less than linear. This less than linear increase in current is as expected since for this size panel the current collection is beganning to approach that for an infinite plane. For an infinite plane the current is constant since the current is at most the thermal flux hitting the sheath boundary.

In the JSC chamber the 9-panel array also went into a glow discharge mode at voltages above 200 volts. In this mode a bright glow appeared over all nine panels and the current was larger than the $20 \mathrm{~mA}$ limit of the power supply. This type of discharge was observed for all positive bias run in the JSCS chamber but was never observed in the LeRC chamber. In order to rule out the possibility that the pressure in the vicinity of the panel was much higher in the JSC chamber than in the LeRC chamber, argon gas was bled into LeRC chamber to increase the pressure to approximately $8 \times 10^{-5}$ torr. Testing at this pressure still did not produce the discharges. The cause of these discharges remain unexplained.

In order to see the voltage profile across the pane1, a Treck electrostatic surface voltage probe was swept across panels 2,5 , and 8 at a distance about $0.3 \mathrm{~cm}$ from the cell surfaces. The voltage sweep was made in both the LeRC and the JSC chambers. At the low voltages, that is, before the current makes its jump, the voltage is limited only to the interconnecting tabs between solar cells. The profile is similar to that shown in Fig. 9 for negative bias except that the peaks are positive. At the high voltages, that is, after the current jump, the whole array is essentially at the applied voltage or slightly below it." A positive voltage trace obtained in the LeRc chamber when the array is at 500 volts is also shown in Fig. 9. As can be seen, the whole array is approximately 50 volts below the applied 500 volts. The large current at the high voltages are, therefore, caused by the whole array surface attracting electrons.

The 9-panel array was also tested under an illumination of one solar constant generated using the carbon arc solar simulator in the JSC facility. With all panels in series, an open circuit voltage of 260 volts and a short circuit current of $43 \mathrm{~mA}$ was measured. The sequence of the series connection was $1-2-3-6-5-4-7-8-9$ with panel 9 being the low end. The current flowing through each panel of the series when the 9-panel array was floating and grounded are shown in Fig. 10. Also shown in the figure for the floating case are the value of the voltage with respect to ground on the high voltage side of each panel. It is seen that the zero voltage point is located somewhere in panel 2. Parts of the 9-panel array float up to 45 volts positive and 203 volts negative wath respect to ground. This agrees with the statement generally assumed that most of a floating array in space would be negative with respect to plasma potential. When the array is grounded, approximately 12 $\mathrm{mA}$ of current is passing through the array. This is comparable to the current collected at 300 volts with an external voltage power supply.

The 9-panel array was also biased with an external power supply connected to panel 9. The results are shown in Fig. 11. Also shown in Fig. 11 are the results for the panel in the dark. With illumination, discharging occurred above a bias of 100 volts, causing the power supply to trip off. Since the solar array itself generates over 200 volts, the voltage for this discharge is over 300 volts which is comparable to the value observed in the dark. Comparing the results with illumination with those obtained in the dark shows that the in-. sulator area effect is active with the internal generated voltage of the array.

\section{Negative Bias}

Disk experiment. The coupling currents versus applied voltage for both disk experiments are shown in Fig. 12. As can be seen the current is almost linear, with voltage for both the plain disk and the 61-cm diameter fiberglass disk. The plain disk current is about a factor of three higher than the fiberglass disk current. This implies that the large fiberglass insulator surrounding the electrode tends to suppress the ion current to the electrode. This result was not observed in previous tests with smaller samples.

Solar array experiments. The coupling currents versus applied voltage for the solar array experiments are shown in Fig. 13. For the single array areing occurred for voltagès higher than 150 volts and for the 9-panel array arcing occurred for voltages higher than 250 volts. These arcs are point blowoff type discharges. Electrons seem to be blown off into the plasma at different points on the array. During arcing there was always a steep rise in current and it was very unstable. 
From Fig. 13 it is also noticed that the coupling current for the 9-panel array rises more gradually than that for the single panel array. This is probably because this large size array tends to collect like an infinite plane.

The surface voltage trace for a negative bras of 500 volts on the 9-panel array is. shown in Fig. 9. Uñlike the case for positive bias at this voltage level, only the interconnecting tabs are at the applied voltage. The solar cell coverslides remain essentially at zero volts.

\section{Concluding Remarks}

Three samples were tested in a plasma of approximately $1 \times 10^{4} \mathrm{el} / \mathrm{cm}^{3}$ in this investigation; (1) a single solar panel of approximately 1400 $\mathrm{cm}^{2}$, (2) a matrix of nine single panels each consisting of approximately $1400 \mathrm{~cm}^{2}$, and (3) a 61 $\mathrm{cm}$ diameter fiberglass disk with a $3.6 \mathrm{~cm}$ diameter electrode in its center. Each of these samples was biased positive and negative to $1 \mathrm{kV}$ or until arcing occurred.

For positive bias, all three samples with insulators showed that the insulator strongly increases the electron current. For all of these samples, there was a steep rise in current for voltages between 100 and 500 volts: Above 500 volts, the current increase was dependent on the size of the sample. For the disk and single array experiments, the current rose almost linearly with voltages above 500 volts. For the 9-panel array the current was tending toward that expected for an infinite plane, that is, the current increased less than linearly with voltage. Also for positive bias, the disk experiment showed that most of the influence of the insulator was limited to a distance less than $10 \mathrm{~cm}$ from the edge of the electrode.

In the large vacuum chamber at JSC for positive biases on the solar array samples, a glow type discharge occurred over the arrays. This discharge was not observed in the smaller chamber at LeRC and could not be initiated by increasing the pressure of argon in the smaller chamber. This phenomenon needs to be investigated further to. see wherher it is real for space conditions or is peculiar only to some ground facilities.

For negative bias, the most serrous phenomenon observed was blowoff type arc discharge occurring on the solar arrays. These arcs have been observed for all size solar arrays. The arcs are not peculiar to facility size or type of gas used to generate the plasma. However, in the voltage range where arcs did not occur, the current was low, varied linearly with voltage, and may be retarded rather than enhanced by the insulator. Therefore, solar arrays operating in this voltage range should not experience any adverse effects.

Current collected by a solar array that is generating its own voltage under illumination is similar to that for an array using an external power supply. This implies that if the physical configuration of an array could be simulated, then reliable plasma testıng could be carried out using external power supplies.

Finally, except for the glow type discharges for positively biased solar arrays, the results show that 15-foot diameter chambers are adequate for testing samples of one square meter at voltages up to $1 \mathrm{kV}$.

\section{References}

1. "Systems Definition on Space-Based Power -Conversion Systems, $\overline{1}$ Boeing Aerospace Co., Seattle, WA, D180-20309-1, 1977, (NASA CR-150209).

2. Grier, N. T. and Stevens, N. J., "P1asma Interaction Experimental (PIX) Flight Results," Spacecraft Charging Technology Conference 1978, NASA CP-2071, pp. 295-314.

3. Grier, N. T., and Domitz, S., "Current From a Dilute Plasma Heasured Through Holes in Insulators," NASA TN D-8111, 1975.

4. Kennerud, K. L., "High Voltage Solar Array Experiments," Boeing Aerospace Co., Seattle, WA. , Mar. 1974 (NASA CR 121280).

5. Domitz, S. and Grier, N. T., "The Interaction of Spacecraft High Voltage Power Systems with the Space Plasma Environment," Power Electronic Specialists Conference, IEEE, N.J. 1974, PP. 62-69.

6. Grier, N. J., and Mckinzie, D. J., Jr., "Measured Current Drainage Through Holes in Various Dielectrics Up to 2 Rilovolts in a Dilute Plasma," NASA TN D-6663, 1972.

7. Cole, R. K., Ogawa, H. S., and Sellen, J. M., . $\mathrm{Jr}$., "Operation of Solar Cell Arrays in Dilute Streaming Plasmas," TRW Systems, Redondo 4 . Beach, CA, TRW-09357-6006-R00, 1968. (NASA CR-72376.)

8. Kaufman, H. R., "Interaction of High Voltage Surfaces with the Space Plasma," Colorado State Univ., Nov. 1979. (NASA CR-159731.)

9. Grier, N. T., "High Voltage Surface-Charged Particle Environment Test Results From Space Flight and Ground Simulation Experiments," NASA TM-79184, 1979. 


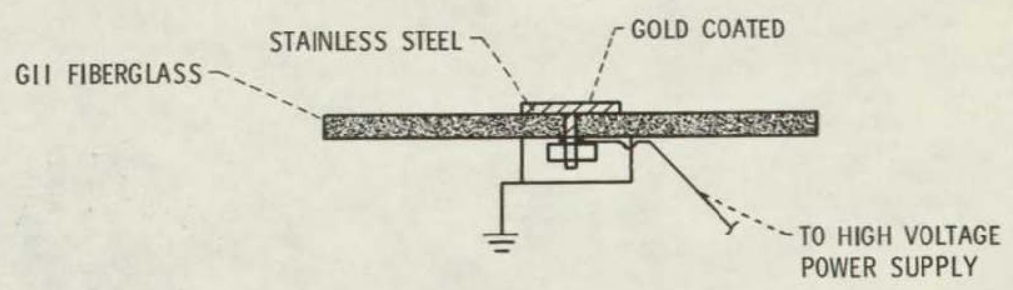

(a) $61 \mathrm{~cm}$ DIAMETER FIBERGLASS DISK.

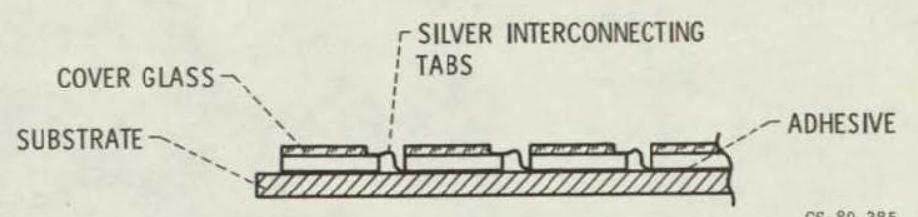

(b) TYPICAL SOLAR ARRAY CONSTRUCTION.

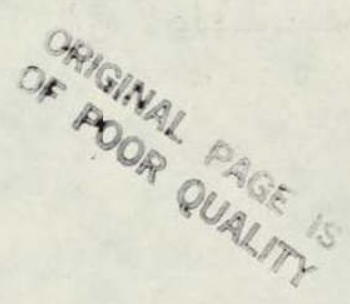

\begin{tabular}{|l|l|l|}
\hline 1 & 2 & 3 \\
\hline 4 & 6 & 5 \\
\hline 7 & 8 & 9 \\
\hline
\end{tabular}

(c) PANEL NUMBERING

FOR NINE-PANEL

SOLAR ARRAY MATRIX.

Figure 1. - Typical solar array construction.

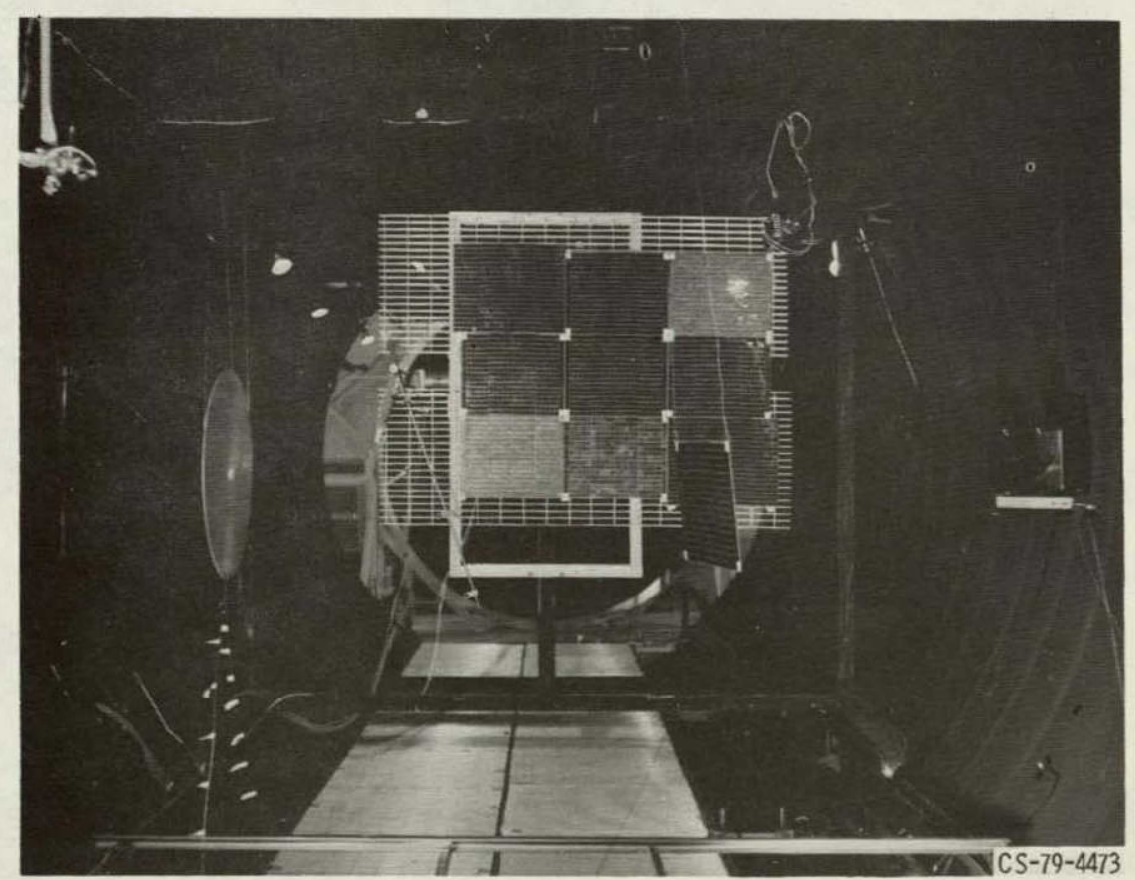

Figure 2. - Experimental set-up in Lewis Research facility (LeRC). 


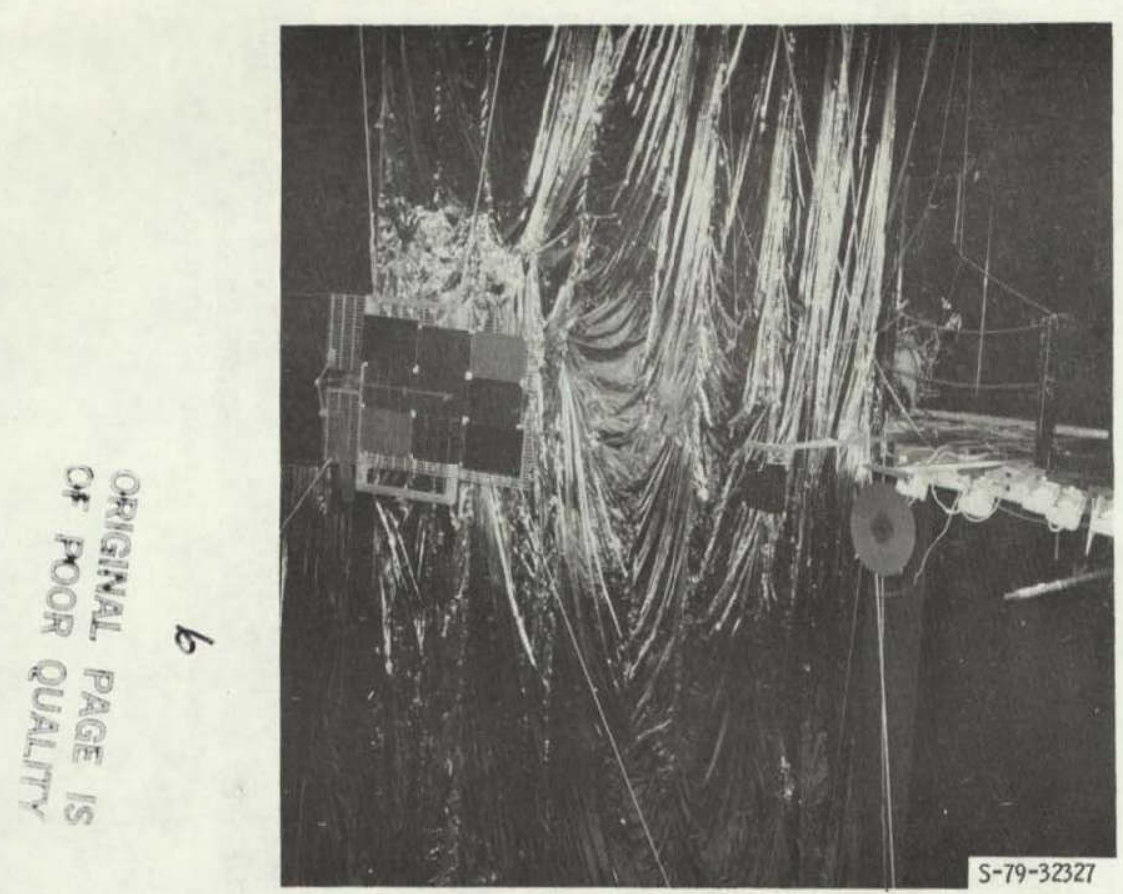

Figure 3. - Experimental setup in Johnson Spaceflight Center (JSC).

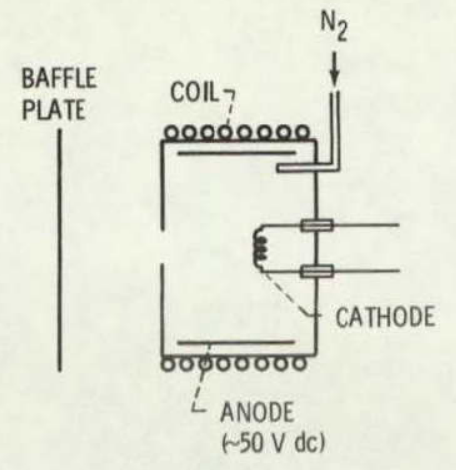

Figure 4. - Plasma generating source for LeRC facility.

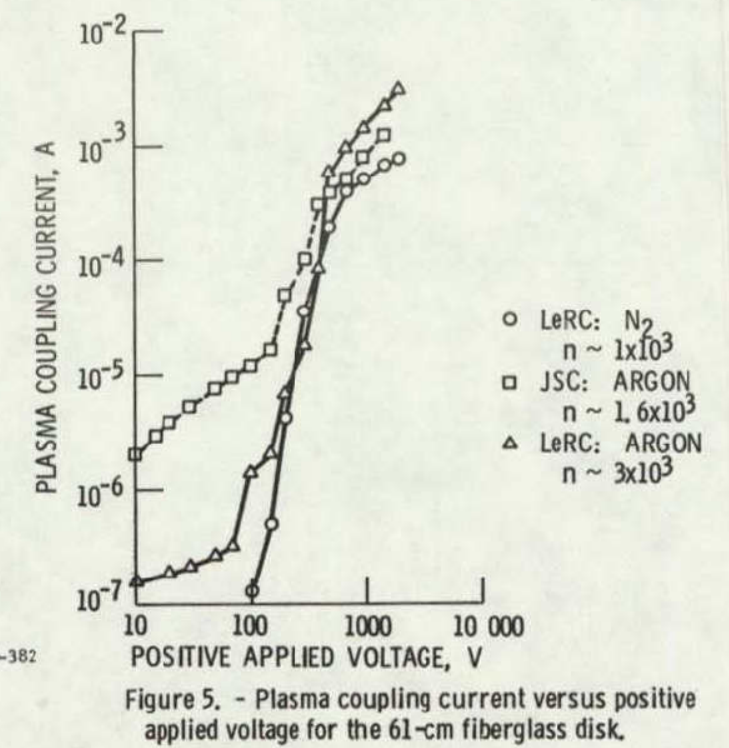




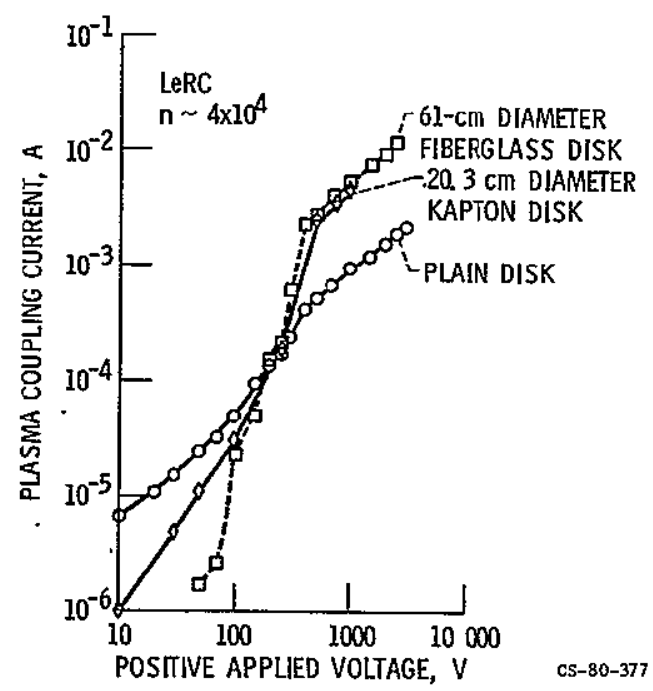

Figure 6. - Comparison of the plasma current for different disk sample as a function of positive applied voltage.

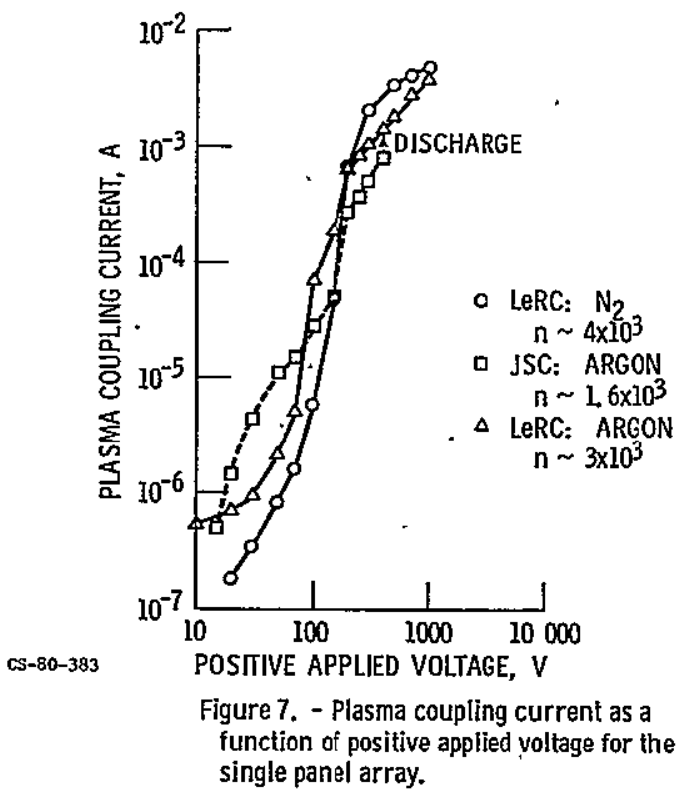




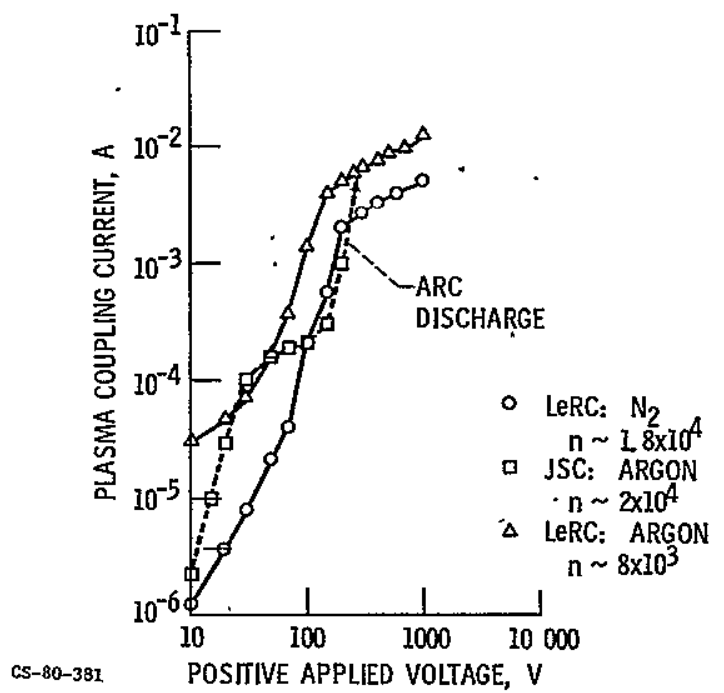

Figure 8. - Plasma coupling current as a function of applied positive voltage for the nine-panel solar array.

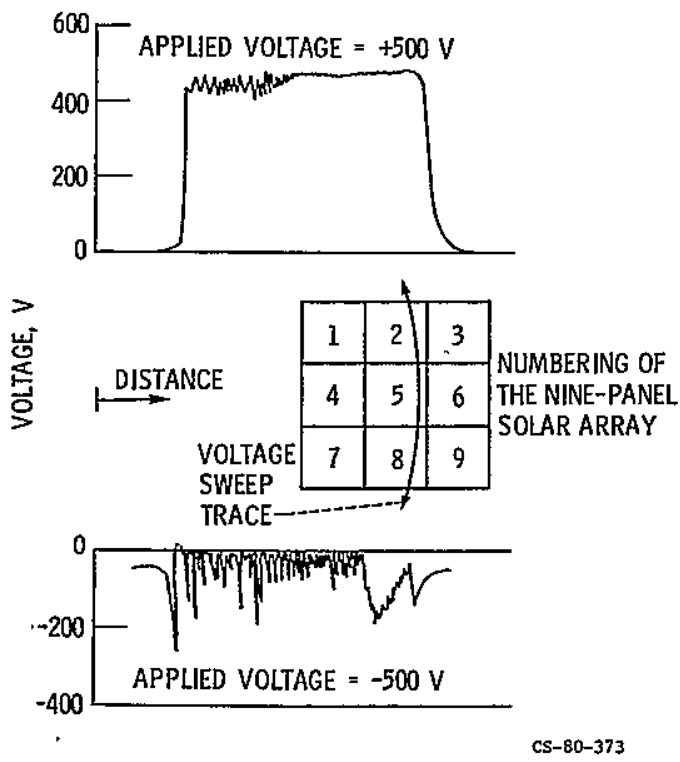

Figure 9. - Typical surface voltage profiles across three solar panels in the nine-panel solar matrix. 


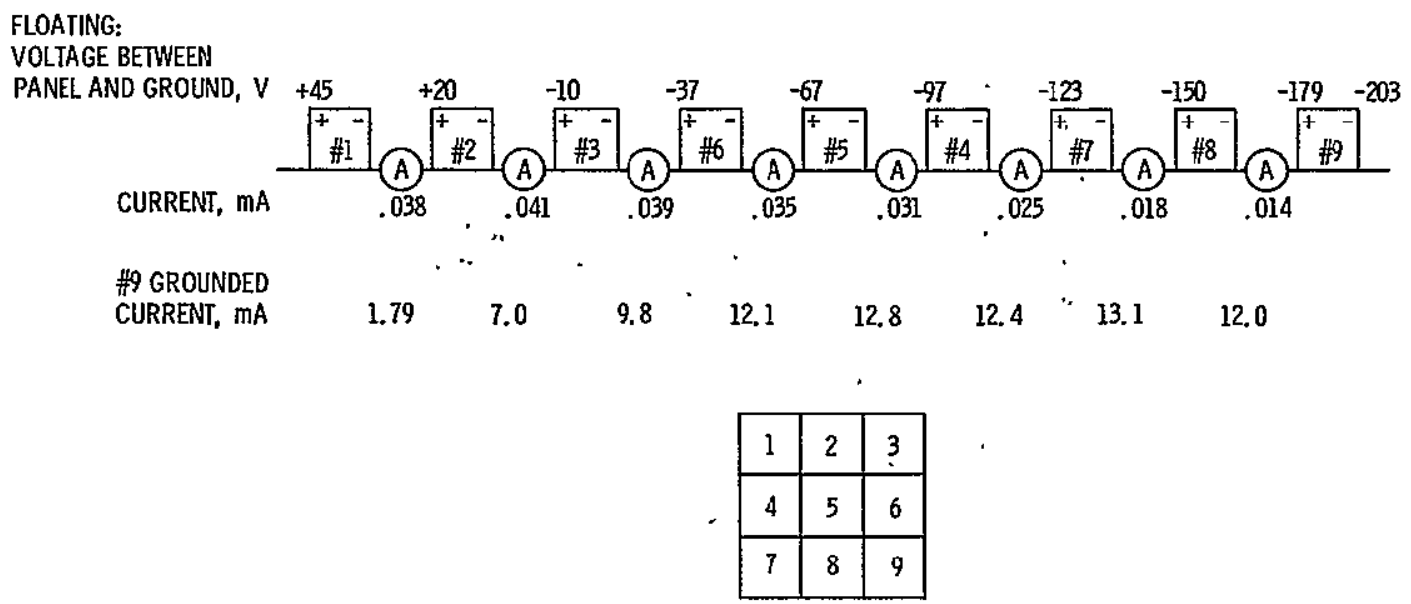

Figure 10. - Current passing between each solar panel of the nine-panel matrix when fully illuminated, floating, and grounded.

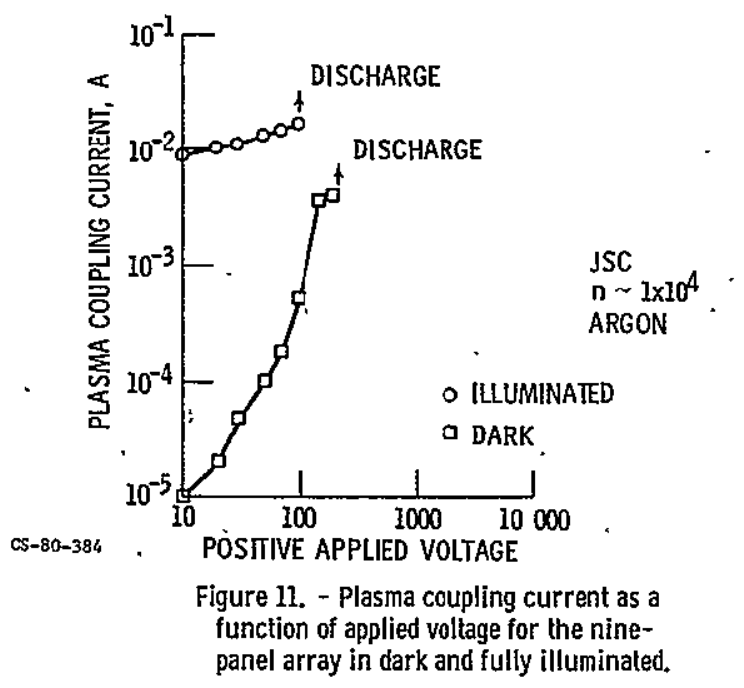




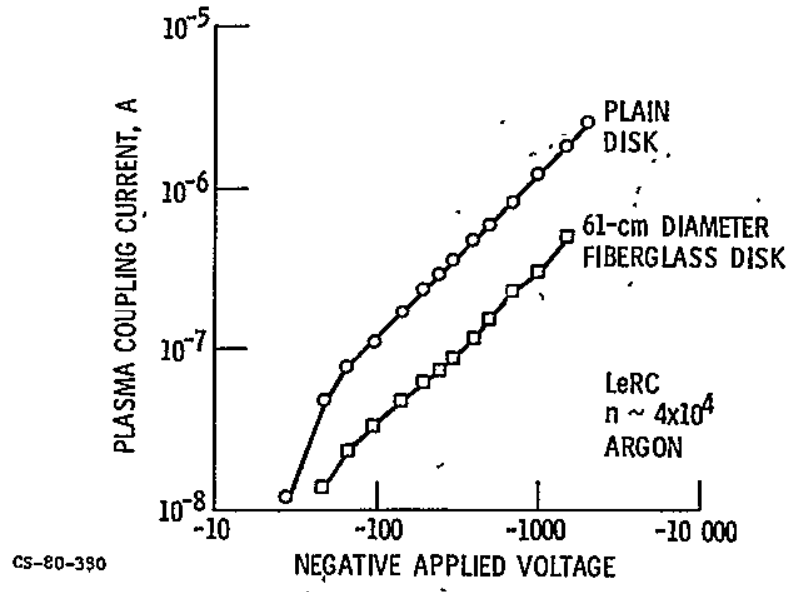

Figure 12. - Plasma coupling current as a function of negative applied voltage for the disks samples.

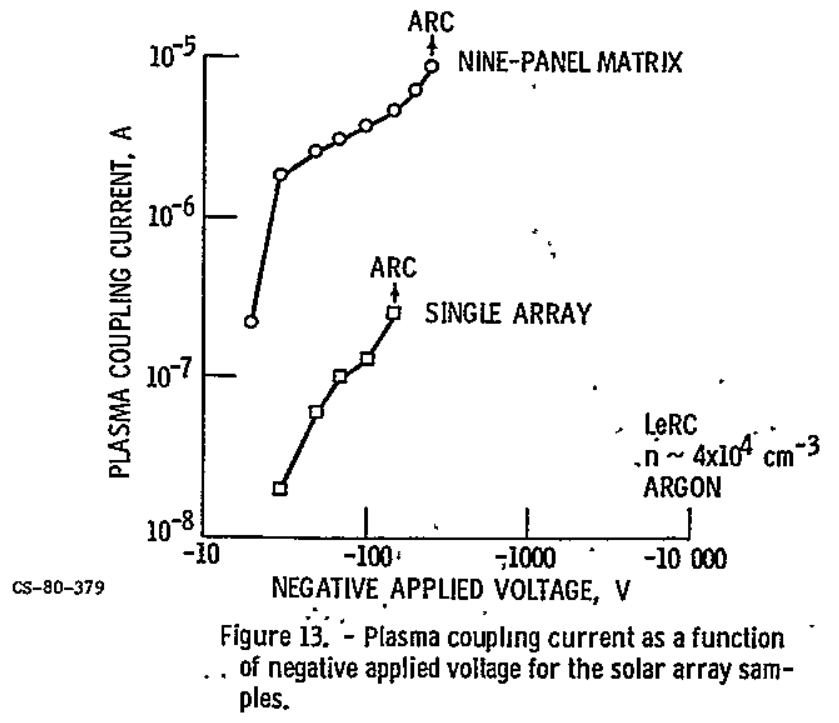


National Aeronautics and Space Administration

SPECIAL FOURTH CLASS MAIL BOOK

Washington, D.C.

20546

Official Business

Penalty for Private Use, $\$ 300$$$
\$ 300
$$

Postage and Fees Paid

National Aeronautics and

Space Administration

NASA-451

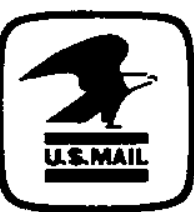

